\title{
La promoción interna restringida a plaza de Técnico de Gestión en los Entes Locales
}

\author{
Antonio M. López González \\ Licenciado en Derecho \\ Jefe de Sección de Asuntos Generales \\ Ayuntamiento de Teror (Las Palmas)
}

\begin{abstract}
Sumario: I. PLANTEAMIENTO.-II. ELEMENTOS SUBJETIVOS. - III. ELEMENTOS OBJETIVOS, CAUSALES Y FINALISTAS.-IV. ELEMENTOS FORMALES. - V. EL EFECTO INDIREC TO EN LOS AUXILIARES ADMINISTRATIVOS DE ADMINISTRACIÓN GENERAL.
\end{abstract}

\section{PLANTEAMIENTO}

La confusión e inseguridad jurídica ${ }^{1}$ habida para crear plazas de régimen funcionarial de grupo de titulación B (en la Ley 30/1984, de 2 de agosto, de medidas para la reforma de la función pública; hoy, subgrupo A2, en la Ley 7/2007, de 12 de abril, del Estatuto Básico del empleado Público) en la Escala de Administración General de Administración Local, ha propiciado soluciones de diverso tipo (crearlas en la Escala de Administración Especial o en la de Administración General, arriesgándose a una impugnación) entre las que se encuentra la de no crear dichas plazas y, sin embargo, crear en la Relación de Puestos de Trabajo (o instrumento análogo) los puestos de trabajo adscribibles a dicho grupo de titulación, pero, adscribiéndolos a plazas de grupo de titulación inferior, como es el caso de las plazas de funcionarios Administrativos de

\footnotetext{
1 «El artículo 22.1 de la Ley 30/1984, de 2 de agosto (EC 1114/84), de Medidas para la Reforma de la Función Pública (LRFP), de carácter básico, y por tanto aplicable a la Administración Local, en su original redacción, definió la promoción interna diciendo que consiste «en el ascenso desde Cuerpos o Escalas de grupo inferior a otros correspondientes de grupo superior», siendo posteriormente el artículo 32.2 del Reglamento aprobado por Real Decreto 2617/1985, de 9 de diciembre (EC 243/86), el que precisó o aclaró que el ascenso por promoción interna procedería únicamente desde un grupo de titulación al Grupo «inmediatamente» superior, norma reglamentaria referida a la inmediatez entre Grupos, que posteriormente se recogió en la modificación de la LRFP llevada a cabo por Ley 23/1988, de 28 de julio (EC 1656/88), y en las normas posteriores que sustituyeron al Reglamento antes citado. La normativa citada, anterior a la reforma de 1988, era la vigente cuando se publicó el Real Decreto Legislativo 781/1986, de 18 de abril (EC 535/86), por el que se aprueba el Texto Refundido de Régimen Local (TRRL), cuyo artículo 169.2 a) establece que la promoción interna a la Subescala Técnica de Administración General (Grupo A) se producirá desde la Subescala Administrativa (Grupo C), exigiendo la titulación y cinco años de servicios en dicha Subescala, lo que evidentemente supone una contradicción con la legislación de la función pública estatal vigente en aquellas fechas y, si bien la norma tenía un carácter de provisionalidad, lo cierto es que las normas posteriores (en especial el Real Decreto 896/1991, de 7 de junio -EC 1944/1991 - ) no la han derogado, por lo que nos encontramos en una situación de «inseguridad jurídica» como para pronunciarnos si el permitir el acceso por promoción interna a los Administrativos a la Subescala Técnica es legal o no y esta inseguridad ni siquiera ha merecido la atención en los acuerdos de FEMP y Sindicatos (EC 2901/95),...». Revista El Consultor de los Ayuntamientos y de los Juzgados, n. ${ }^{\circ}$ 17/1996, Consulta con referencia número 2449/1996.
} 
Administración General suficientemente cualificados por disponer de la titulación idónea.

Pero, una vez que la Ley 53/2002, de 30 de diciembre, de medidas fiscales, administrativas y del orden social (art. 60.1), ha creado dicho grupo de titulación $\mathrm{B}$, surge una importante expectativa de promoción interna excepcional con reserva total de vacantes (restringida) para esos funcionarios Administrativos que, históricamente, han desempeñado funciones de grupo de titulación superior.

\section{ELEMENTOS SUBJETIVOS}

Los sujetos principales de la relación jurídica constituida por esta modalidad de promoción interna excepcional son la Administración local actuante, la Mesa de Negociación Colectiva competente según los art. 34 y 35 de la Ley 7/2007, de 12 de abril, del Estatuto Básico del Empleado Público, los funcionarios Administrativos de Administración General que vienen desempeñando funciones propias de grupo de titulación superior y los otros funcionarios Administrativos de la misma organización que desempeñan funciones propias de su plaza y que tienen derecho a participar en el proceso selectivo de promoción interna si reúnen el requisito de titulación.

\section{ELEMENTOS OBJETIVOS, CAUSALES Y FINALISTAS}

La relación jurídica constituida por esta modalidad de promoción interna excepcional tiene dos componentes objetivos básicos:

a) El supuesto de hecho, integrado, a su vez, por los siguientes hechos determinantes:

- La obstaculización histórica a la promoción interna de los funcionarios Administrativos de la Escala de Administración General de Administración Local.

- La existencia de funcionarios Administrativos de Administración General de Administración Local que vienen desempeñando, desde hace años o tiempo inmemorial, funciones propias de grupo de titulación superior.

- La creación, por primera vez, del Cuerpo de Técnicos de Gestión en el modelo general de función pública local por la Ley 53/2002 y, en el modelo propio de función pública de cada Administración Pública Local, en el momento de adoptarse dicha decisión.

b) La consecuencia jurídica, que viene determinada por la elección de la solución más ventajosa, para esos funcionarios Administrativos que vienen des- 
empeñando funciones de grupo de titulación superior, de entre las diferentes soluciones organizativas y de gestión de recursos humanos que la Administración Pública actuante puede adoptar, en ejercicio de su potestad de autoorganización, sin vulnerar los principios de igualdad en el acceso a la función pública, mérito y capacidad (arts. 23.2 y 103.2 de la Constitución).

La obstaculización histórica al derecho de promoción profesional de los funcionarios Administrativos de Administración Local se fundamenta en un hecho objetivo: la inexistencia de grupo de titulación B, y de plaza adscribible al mismo, en la Escala de Administración General de Administración Local hasta la Ley 53/2002. La acreditación de este hecho resulta de la simple contratación de la normativa invocada.

Por otro lado, la inseguridad jurídica que ello ha causado en las posibilidades de promoción profesional de los funcionarios Administrativos, antes de la Ley 53/2002, también se haya acreditada por la doctrina científica que da buena cuenta de ello ${ }^{2}$.

La existencia de funcionarios Administrativos de Administración General de Administración Local que vienen desempeñando funciones propias de grupo de titulación superior ha de acreditarse mediante un análisis y estudio de puestos de trabajo que constate tal circunstancia y las figuras jurídicas de provisión temporal de puestos de trabajo ${ }^{3}$ utilizadas, como pudieran ser las comisiones de servicios intraorgánicas, las atribuciones temporales de funciones, los nombramientos provisionales o los nombramientos definitivos en puesto de trabajo adscrito a plaza de grupo de titulación inferior. El análisis de puestos debe dejar acreditado que entre las funciones del puesto de trabajo adscrito a plaza de Administrativo existe un solapamiento de funciones propias de plaza de grupo de titulación superior y que dichas funciones solapadas constituyen el núcleo esencial funcional del puesto de trabajo. En todos estos casos se produce una provisión de puestos irregular en fraude de ley, causada por la vulneración del principio de proporcionalidad, dado que, por un lado, se incumple el requisito de temporalidad por la duración desproporcionada de la provisión temporal, en su caso, y, por otro lado, la atribución de funciones propias de grupo de titulación superior, que se configuran como núcleo funcional esencial del puesto de trabajo, vulnera el principio de idoneidad ${ }^{4}$ entre plaza funcionarial, puesto de trabajo, núcleo funcional esencial y grupo de titulación.

2 Martín Bautista, María Teresa, «La creación de la Subescala de Gestión (Grupo B) en la Escala de Administración General: más vale tarde que nunca», El Consultor de los Ayuntamientos y de los Juzgados N. ${ }^{\circ}$, Quincena 30 Mar.-14 Abr. 2003, Ref. a 1081/2003, pág. 1081, Tomo 1.

3 Martín Bautista, María Teresa, «Las formas de provisión temporal de los puestos de trabajo. Un análisis desde la perspectiva de la Función Pública Local», El Consultor de los Ayuntamientos y de los Juzgados N. ${ }^{\circ}$, Quincena 15-29 Abr. 2002, Ref. ${ }^{a}$ 1182/2002, pág. 1182, Tomo 1.

4 «El contenido de los actos se ajustará a lo dispuesto por el ordenamiento jurídico y será determinado y adecuado a los fines de aquellos» (art. 53.2 de la Ley 30/1992, de 26 de noviembre, de régimen jurídico de las administraciones públicas y del procedimiento administrativo común). 
La creación, por primera vez, del Cuerpo de Técnicos de Gestión en el modelo de función pública local de cada entidad local es un hecho determinante acreditable a través del análisis del estado actual de la plantilla de personal funcionario de su organización respectiva.

Entre las posibles soluciones organizativas y de gestión de recursos humanos que la Administración pública actuante puede adoptar, en ejercicio de su potestad de autoorganización, se halla la aprobación y ejecución de una promoción interna excepcional restringida, dado que esta opción no vulnera los principios de igualdad, mérito y capacidad, según la doctrina del Tribunal Constitucional relativa a las pruebas restringidas o específicas para el acceso al empleo público o promoción profesional en el mismo.

Esta doctrina del Tribunal Constitucional está vigente y es derecho de directa aplicación ${ }^{5}$, lo que ocurre es que el supuesto de hecho es tan excepcional que rara vez puede darse. Dice el Tribunal Constitucional que las «pruebas específicas» (STC 27/1991 y 302/1993) o «pruebas restringidas o específicas» (STC 60/1994) sólo son admisibles en el caso excepcional, por ser único e irrepetible, de la construcción de un poder público emergente aún no dotado de una función pública propia y con la finalidad de consolidar una situación precedente de precariedad en el empleo público.

Esta doctrina del Tribunal Constitucional se originó en el marco de la construcción de la Administración Pública de las Comunidades Autónomas y es aplicable, plenamente, al caso concreto de la creación, por primera vez en cada Entidad Local, del Cuerpo propio de Técnicos de Gestión, a partir de los funcionarios Administrativos de Administración General que, efectivamente, vengan desempeñando las funciones propias de dicho cuerpo funcionarial de nueva creación. Los criterios rectores de la plena aplicación, a este caso, de la doctrina constitucional referida son los siguientes:

- El principio de analogía del art. 4 del Código Civil: «Procederá la aplicación analógica de las normas cuando éstas no contemplen un supuesto específico, pero regulen otro semejante entre los que se aprecie identidad de razón».

- La tensión existente entre la interpretación restrictiva de «lo excepcional» de la prueba restringida (para acceso a la función pública o para la promoción interna de quienes ya son empleados públicos) y la interpretación

\footnotetext{
5 La interpretación del TC, «en el ámbito de su específica competencia, constituye ...regla vinculante (arts. 164 de la Constitución y 38 de la Ley orgánica 2/ 1979, de 3 de octubre, del Tribunal Constitucional)...» (STC, 6/1991, de 15 de enero, FJ 4). El Tribunal Constitucional, Sala 1. a, ha expuesto un reciente resumen de su doctrina sobre los sistemas de acceso restringido al empleo público en el F.D. 3. ${ }^{\circ}$ de su Sentencia de 2710-2008, n. ${ }^{\circ}$ 126/2008, rec. 2005/2000, Pte.: Pérez Tremps, Pablo. Y el art. 61.1 de la Ley 7/2007, los establece para la promoción interna y para medidas de discriminación positiva (personas discapacitadas).
} 
extensiva ${ }^{6}$ en materia de derechos fundamentales (el derecho de acceso al empleo público de quienes aún no son empleados públicos), la resuelve el Tribunal Constitucional dando prevalencia a la primera, al considerar que el art. 23.2 de la Constitución no establece un derecho público subjetivo, sino un interés legítimo o derecho público reaccional ${ }^{7}$.

- El art. 35 de la constitución establece el derecho a la promoción en el trabajo como principio rector de la política social y económica de los poderes públicos. Este precepto no es de aplicación directa, pero sí «informará la actuación de los poderes públicos de acuerdo con las leyes que los desarrollen» y conforme al mandato de igualdad material del art. 9.2 de la Constitución, que impone a los poderes públicos el deber de «remover los obstáculos que impidan o dificulten» la realidad y efectividad de la libertad e igualdad del individuo y de los grupos en que se integra, pudiendo, para ello, aplicar un trato diferenciado a determinados colectivos de ciudadanos:

«Ślo le resulta posible al legislador, en adecuada opción legislativa, establecer para los ciudadanos un trato diferenciado, cuando tenga que resolver situaciones diferenciadas fácticamente con mayor o suficiente intensidad, que requieran en su solución por su mismo contenido una decisión distinta,...» (TC Pleno, S. de 3-8-1983, n. ${ }^{\circ}$ 75/1983, rec. 44/1982. F.D. 2. ${ }^{\circ}$ ). El art. 61.1 de la Ley $7 / 2007$ es desarrollo de este principio rector (ver nota 5 ).

La solución organizativa de la promoción interna restringida no vulnera los principios de igualdad, mérito y capacidad, pues, en palabras del propio Tribunal Constitucional,

«...La previsión legal de pruebas específicas para consolidar una situación precaria precedente no lesiona aquí los arts. 23.2 y $103.2 \mathrm{CE}$, ya que viene "derivada de un proceso único e irrepetible de creación de una nueva forma de organización de las Administraciones Públicas a nivel autonómico"...» (STC 302/1993, STC 60/1994, STC 27/1991).

6 Es doctrina reiterada del TC que «la legalidad debe ser interpretada en el sentido más favorable a los derechos fundamentales» (SS 34/83, de 6 de mayo; 17/85, de 9 de febrero; 57/85, de 29 de abril y 24/90, de 15 de febrero).

7 «CUARTO. -...El art. 23.2 CE garantiza a todos los ciudadanos (y sólo a ellos) el derecho de acceder en condiciones de igualdad a las funciones y cargos públicos, con los requisitos que señalen las leyes. No nace de este precepto ...derecho alguno a la ocupación de cargos o al desempeño de funciones determinados, y ni siquiera derecho a proponerse como candidato para los unos o las otras. El derecho a_tomar parte en el procedimiento (selectivo o electivo) que ha de llevar a la designación y 'a fortiori' el derecho a esta misma, sólo nace de las normas legales o reglamentarias que disciplinan, en cada caso, el acceso al cargo o función en concreto. Lo que, como concreción del principio general de igualdad, otorga el art. 23.2 a todos los españoles es un derecho de carácter puramente reaccional para impugnar ante la jurisdicción ordinaria y en último término ante este Tribunal, toda norma o toda aplicación concreta de una norma que quiebre la igualdad» (Tribunal Constitucional Sala 1. a, S 23/4/1986, n. ${ }^{\circ}$ 50/1986, BOE 120/1986, de 20 de mayo de 1986, rec. 511/1985.). 
«Es evidente que el derecho a la igualdad en el acceso a la función pública supone una limitación fundamental a la práctica de las llamadas 'pruebas restringidas' para el acceso a la función pública, ...si bien, no cabe excluir que, en determinados casos excepcionales, la diferencia de trato ...pueda considerarse como razonable, proporcionada y no arbitraria a los efectos de la desigualdad de trato que establece, siempre que dicha diferenciación se demuestre con un medio excepcional y adecuado para resolver una situación también excepcional, expresamente prevista en una norma con rango de Ley y con el objeto de alcanzar una finalidad constitucionalmente legitima, entre las que se integra también la propia eficacia de la Administración Pública» (Tribunal Constitucional Pleno, S 14-2-1991, n. ${ }^{\circ}$ 27/1991, BOE 64/1991, de 15 de marzo de 1991, rec. 1359/1986).

«...es diferente el rigor e intensidad con que operan los principios de mérito y capacidad según se trate del inicial ingreso en la función pública o del ulterior desarrollo o promoción de la propia carrera administrativa, pues en el supuesto de provisión de puestos de trabajo entre personas que ya han accedido a la función pública y, por ende, acreditado los requisitos de mérito y capacidad, cabe tener en cuenta otros criterios distintos enderezados a lograr una mayor eficacia en la organización y prestación de los servicios públicos o a satisfacer otros bienes constitucionalmente protegidos (SSTC 192/1991 y 200/1991)» (STC 365/1993, de 13 de diciembre, FJ 7)» (Tribunal Constitucional Sala 1. a, S. 25-2-2008, n. ${ }^{\circ} 30 / 2008$, rec. 6452/2002, 3049/2004).

La doctrina del Tribunal Constitucional referida regula también los elementos causales y finalistas que han de integrar la relación jurídica de promoción interna restringida. La causa radica, en estos casos, en la inexistencia de un modelo propio de función pública (el autonómico), que, en el caso de la Administración Pública Local estaba inacabado y provocando la obstaculización histórica de la posibilidad de fomentar la carrera profesional de los funcionarios Administrativos de Administración General. En cuanto a los fines legítimos que se pueden asignar a una prueba restringida, el TC, enumera los siguientes, todos ellos aplicables a la modalidad de promoción interna aquí propuesta: 1) Asegurar la eficacia de la Administración Pública ${ }^{8}$, y; 2) Resolver un problema de precariedad en el empleo público 9 .

\footnotetext{
8 «...resolver una situación también excepcional, expresamente prevista en una norma con rango de Ley y con el objeto de alcanzar una finalidad constitucionalmente legitima, entre las que se integra también la propia eficacia de la Administración Pública. ...Mediante tales disposiciones lo que se persigue exclusivamente es atender a las expectativas de acceso a la función pública creadas por la necesidad de instaurar una nueva Administración autonómica y contribuir a la estabilidad y eficacia de la misma» (STC 27/1991, de 14/2/1991, rec. 1359/1986).

9 «... la finalidad de consolidar el empleo público temporal no puede considerarse a priori ilegítima, ya que pretende conseguir estabilidad en el empleo para quienes llevan un periodo mas o menos prolongado de tiempo desempeñando satisfactoriamente las tareas encomendadas...» (STC 107/2003, de 2 de junio).
} 


\section{ELEMENTOS FORMALES}

Los elementos formales de la relación jurídica analizada son los siguientes: habilitación legal, procedimiento y motivación.

La habilitación legal ${ }^{10} \mathrm{y}$ el procedimiento a seguir vienen establecidos por el art. 18 y D.A $21 .^{a}$ de la Ley 30/1984, de medidas para la reforma de la función pública, modificada por la Ley 22/1993 que creó la figura jurídica del Plan de Empleo, coincidiendo con la etapa de consolidación de la doctrina del Tribunal Constitucional sobre las pruebas restringidas o específicas para el acceso al empleo público o para la promoción profesional en él (TC, Ss. 27/1991, 302/1993 y 60/1994).

Estas normas prevén dos instrumentos jurídicos para implementar «medidas específicas de promoción interna»: el Plan de Empleo y las actuaciones concretas propias de un plan de empleo aprobadas y ejecutadas de forma independiente. El plan de empleo debe someterse a un periodo de información pública de treinta días, lo que no se exige para el caso de las actuaciones independientes, pero, con el fin de garantizar una mínima publicidad a este tipo de medidas independientes, deben incluirse, al menos, en la Oferta de Empleo Público como medidas de planificación de recursos humanos ${ }^{11} \mathrm{o}$, de no anunciarse así, las bases reguladoras del procedimiento selectivo por promoción interna restringida deberán someterse a un periodo de información pública de, al menos, veinte días, en aplicación del art. 86 de la Ley 30/1992, de 26 de noviembre, de régimen jurídico de las administraciones públicas y del procedimiento administrativo común, dado que se afecta al interés legítimo en el acceso al empleo público de quienes carecen de la condición de funcionario (art. 23.2 de la Constitución).

Los criterios generales de estas medidas específicas deben ser objeto de negociación colectiva ${ }^{12}$.

La motivación de la excepcionalidad de la promoción interna es un requisito formal necesario pues, $1 .^{\circ}$ ) los motivos que expresa limitan el «interés legítimo» ${ }^{13}, 14$ de quienes no tienen la condición de empleados públicos, en el acceso igualitario a la función pública; $2^{\circ}$ ) acredita la excepcionalidad y viabilidad de la solución organizativa propuesta (en función de sus elementos objetivo, causal y finalista y por ser única e irrepetible); y $3 .^{\circ}$ ) resulta imprescindi-

\footnotetext{
10 «Es esta situación excepcional y transitoria la que, mediante la pertinente habilitación legal, puede justificar este sacrificio de la igualdad de trato...» (STC 27/1991).

11 «La Oferta de empleo público o instrumento similar podrá contener medidas derivadas de la planificación de recursos humanos» (art. 70.2 de la Ley 7/2007, de 12 de abril, del Estatuto Básico del Empleado).

12 «Serán objeto de negociación ...las materias siguientes: ...f) Los criterios generales de los planes y fondos para la formación y la promoción interna» (art. 37.1 de la Ley 7/2007, de 12 de abril, del Estatuto Básico del Empleado).

13 Art. 54 de la Ley 30/1992, de 26 de noviembre, de régimen jurídico de las administraciones públicas y del procedimiento administrativo común: «Serán motivados ...los actos que limiten ...intereses legítimos».

14 Ver nota 7.
} 
ble para el control judicial de la actividad administrativa y para evitar el fraude de ley consistente en presentar, como restringida, una promoción interna que debería reservar plazas para acceso libre ${ }^{15}$.

\section{EL EFECTO INDIRECTO EN LOS AUXILIARES ADMINISTRATIVOS DE ADMINISTRACION GENERAL}

En las Administraciones públicas locales de pequeña dimensión la promoción interna es casi siempre una cuestión generacional que viene determinada por la jubilación de algún funcionario (o por otras circunstancias con similar efecto causante de vacante: fallecimiento, alguna situación administrativa de larga duración, movilidad).

Es por ello que la excepción aplicable, directamente, a los funcionarios Administrativos, lo es, también, indirectamente, a los funcionarios Auxiliares Administrativos; principalmente, en el caso extremo de que los Auxiliares Administrativos no hayan ejercido el derecho a la promoción interna durante todo el tiempo en el que hayan habido funcionarios Administrativos desempeñando funciones de grupo de titulación superior, pues, en tal caso, es evidente que la falta de promoción de los Administrativos ha obstaculizado a la de los Auxiliares.

Esta promoción interna a favor de los Auxiliares Administrativos ha de referirse a un número de plazas igual (y no superior) al de plazas resultantes de la promoción interna restringida de los funcionarios Administrativos.

15 TS, Sala 3.a , sec. 7. a, S. 25/01/2006, rec. 6314/1999: pruebas selectivas para cubrir 710 plazas en el Cuerpo General en la Administración del Estado, por el sistema de promoción interna, desde Cuerpos o Escalas del Grupo D. 